\title{
Preparation, Characterization and Properties of Films Obtained from Cross-linked Guar Gum
}

\author{
Rodrigo S. Banegas, Clarice F. Zornio, Adriana de M. G. Borges, Ledilege C. Porto, Valdir Soldi \\ Departamento de Química, UFSC
}

\begin{abstract}
In this study the viability of using guar gum to form films was investigated along with the effectiveness of the cross-linking process employing 1-ethyl-3-(3-dimethylaminopropyl) carbodiimide hydrochloride (EDC) as the cross-linking agent. In addition, the cross-linked films were evaluated considering the water absorption, thermal stability and mechanical properties. The cross-linking process of guar gum films was confirmed by the low solubility in water and through infrared analysis. The results shown that the properties evaluated were affected by the cross-linking process due to changes in the polysaccharide structure. For example, the swelling behavior and water vapor absorption decreased with an increase in the amount of EDC. The EDC content (10-30\%) also affected the polymer structure and hydrogen bond formation, reducing the thermal stability of the system.
\end{abstract}

Keywords: Guar gum films, cross-linking process, water absorption, EDC.

\section{Introduction}

Polysaccharides are widely used as gelling and stabilizing agents in food products and various attempts have been made to relate their microstructure to these properties ${ }^{[1-3]}$. Natural polymers, such as polysaccharides, have become increasingly important because of their low cost, high availability, low toxicity and biodegradability ${ }^{[4]}$. In particular, in the pharmaceutical area, their application as agents for cell adhesion and growth and as drug delivery systems has been exploited ${ }^{[5-7]}$.

Guar gum (GG) is a natural polysaccharide extracted from Cyamopsis tetragonoloba seeds. Chemically, it consists of a linear long chain molecule of $\beta(1 \rightarrow 4)$-linked D-mannose residues with single linked $\alpha(1 \rightarrow 6)$-D-galactose ${ }^{[8-10]}$. The ratio of mannose to galactose units (M/G) varies from 1.5:1 to 1.8:1 depending on climatic variations ${ }^{[11]}$. It has been used for different industrial purposes related to foods, pharmaceuticals, nutrition and cosmetics ${ }^{[12]}$. Among other properties, GG is highly soluble in water and is able to form homogeneous edible films. Its full solubility, due to the great number of hydroxyls found in its structure, can be a disadvantage depending on the application $^{[13]}$. One alternative used to reduce the solubility and to improve the thermal and mechanical properties is the addition of cross-linking agents ${ }^{[14]}$. According to the literature, only a few agents have been used to cross-link GG. For example, Gliko-Kabir et al. ${ }^{[15-17]}$ studied the cross-linking of GG using glutaraldehyde and trisodium trimetaphosphate. The systems were evaluated in terms of the thermal behavior and the viability of their use as delivery systems. In other study, Burruano et al. ${ }^{[18]}$ evaluated the cross-linking of GG with sodium borate solution and reported that the process was efficient in terms of reducing the solubility. Also, Chaurasia et al. ${ }^{[19]}$ prepared cross-linked guar gum microspheres using glutaraldehyde as a crosslinking agent. In the same study the authors studied different formulations and parameters that could affect the preparation and properties of the microspheres in order to optimize the process used to obtain small, discrete, uniform, smooth-surfaced and spherical microspheres.

In our study, was used 1-ethyl-3-(3-dimethylaminopropyl) carbodiimide hydrochloride (EDC) as the cross-linking agent, which is known to be of low toxicity and has been found to modify side-groups on proteins and polysaccharides. Cross- linking with carbodiimides is of particular interest in terms of biological applications because it does not remain in the GG structure, since it is released forming a urea derivative which can be removed by washing with water. Characteristics such as the low toxicity and the simple removal of the sub-products (urea) are advantageous in comparison to formaldehyde and glutaraldehyde which have been extensively used to cross-link polysaccharides and proteins ${ }^{[20,21]}$. Carbodiimides have been used, for example, to cross-link blends of collagen and polyvinyl alcohol and shown to be more efficient in the release of a growth hormone than the same system cross-linked with glutaraldehyde ${ }^{[22]}$. Liang et al. ${ }^{[23]}$ studied hydrogels of gelatin cross-linked with EDC and genipin lattices. The authors observed that carbodiimides can form intra- and intermolecular bonds in gelatin. Macroporous and nanofibrous gelatin scaffolds cross-linked with EDC were studied by Liu et al. ${ }^{[24]}$ and the results showed their great dimensional stability when used as a support for tissue regeneration. Kolodziejska and Piotrowska ${ }^{[25]}$ evaluated the water vapor permeability, mechanical properties and solubility of films of gelatin and chitosan chemically modified with transglutaminase or EDC using glycerol as a plasticizer. The results showed that the cross-linking process in the presence of glycerol does not improve the barrier and mechanical properties.

The goal of this paper was to evaluate the viability to form films from guar gum cross-linked by 1-ethyl-3-(3-dimethylaminopropyl) carbodiimide hydrochloride (EDC) as the cross-linking agent. In addition, the cross-linked system was evaluated considering the water solubility, swelling behavior, water vapor absorption, thermal stability and mechanical properties.

\section{Experimental}

\section{Materials}

Guar gum (GG) and 1-ethyl-3-(3-dimethylaminopropyl) carbodiimide hydrochloride (EDC) were purchased from SigmaAldrich (St. Louis, USA). Ethanol, ether and acetone were purchased from Nuclear (SP, Brazil) and Span 80, Tween 80 and castor oil were purchased from Vetec (RJ, Brazil).

With the exception of guar gum, the other materials were used without further purification.

Corresponding author: Valdir Soldi, Departamento de Química, Universidade Federal de Santa Catarina - UFSC, CEP 88040-900, Florianópolis, SC, Brazil, e-mail:vsoldi@pq.cnpq.br; soldi.valdir@ufsc.br 


\section{Guar gum purification}

The guar gum was purified through the method described by Cunha et al. ${ }^{[26]}$. The GG was boiled for 10 minutes in a solution of $80 \%$ ethanol (v/v), filtered and the residue washed with ethanol, acetone and ether. The GG was stirred for one hour to complete hydration, and the solution was then centrifuged at 2000 RPM for 15 minutes. The supernatant was precipitated with two volumes of acetone. The GG was re-dissolved under stirring for 24 hours and the solution was centrifuged at 6000 RPM for 1.5 hours. The supernatant was precipitated with two volumes of ethanol, washed with acetone and dried in hot air.

Non-purified and purified GG films were analyzed by SEM microscopy (figures not shown). The non-purified films had a heterogeneous and rough surface while the purified ones were homogeneous and smooth and apparently without porosity.

\section{Film formation}

The film-forming solution was prepared by dissolving $0.5 \mathrm{~g}$ of guar gum $(1 \% \mathrm{wt} / \mathrm{v})$ in $50 \mathrm{~mL}$ of distilled and deionized water $(\mathrm{pH}=6.8 \pm 0.2)$ under stirring for 24 hours. A concentration of $1 \%$ of guar gum was used in order to obtain films with $c a .0 .2$ micrometers of thickness. After total solubilization, the solution was placed in a Teflon petri dish for solvent evaporation under ambient conditions. The films formed were carefully removed from the petri dish and stored in desiccators for later use.

For the cross-linking process, an appropriate amount (10-30\%,w/w) of 1-ethyl-3-(3-dimethylaminopropyl) hydrochloride (EDC) was added to the film-forming solution. After the addition of the EDC, the solution was left for around 5 minutes and spread onto a Teflon petri dish, dried and stored in desiccators for later use.

\section{Fourier-transform infrared spectroscopy}

Fourier-transform infrared (FTIR) spectra were obtained on a Perkin-Elmer PC-16 spectrometer with a resolution of $4 \mathrm{~cm}^{-1}$, in the range of 4000-400 $\mathrm{cm}^{-1}$. The FTIR analysis was performed using $0.2 \%(\mathrm{~m} / \mathrm{v}) \mathrm{GG}$ films at $25^{\circ} \mathrm{C}$.

\section{Water absorption, swelling ratio and solubility}

The swelling ratio (SR) was measured as a function of time. In this procedure, pre-weighed pieces of cross-linked GG films, dried in a vacuum oven until constant weight, were immersed in distilled water at room temperature under controlled stirring. At different time intervals, samples were taken from the water, the film surfaces were dried with filter paper and the swollen samples were weighed. The SR was calculated as the ratio between the swollen and dry sample weights. The experiment was carried out in triplicate.

For the water solubility tests, the films were first cut into small pieces $(3 \mathrm{~cm} \times 3 \mathrm{~cm})$ and kept in a drying oven at $60{ }^{\circ} \mathrm{C}$ for 24 hours. The dried films were placed in a desiccator for approximately 20 minutes to reach the equilibrium temperature $\left(25^{\circ} \mathrm{C}\right)$ and the initial weight $\left(\mathrm{m}_{1}\right)$ was determined. The weighed films were immersed in $50 \mathrm{~mL}$ of water for 24 hours. The films were then removed from the water and dried in an oven for 48 hours at $80{ }^{\circ} \mathrm{C}$. The films were again stored in a desiccator for approximately 20 minutes before the determination of the final weight $\left(\mathrm{m}_{2}\right)$. The solubility $(\mathrm{S})$ was calculated through Equation 1 , where $\mathrm{m}_{1}$ and $\mathrm{m}_{2}$ are the sample weights before and after the immersion in water, respectively.

$$
S=\frac{m_{2}-m_{1}}{m_{1}} \times 100
$$

The water vapor absorption (WVA) was determined according to the method described by Angles and Dufresne ${ }^{[27]}$. The samples $(2 \times 2 \mathrm{~cm})$ were stored in a vacuum oven to remove the moisture. The pre-weighed samples were conditioned at room temperature in a desiccator under a constant relative humidity of $98 \%$. At predetermined time intervals the samples were removed and weighed. The WVA was calculated according to Equation 1, where $\mathrm{m}_{2}$ and $\mathrm{m}_{1}$ are the sample weights after and before the exposure to $98 \%$ relative humidity, respectively.

\section{Thermogravimetric analysis}

The thermal stability of the samples was evaluated through thermogravimetry using a TGA 50 instrument (Shimadzu). Measurements were taken from $25{ }^{\circ} \mathrm{C}$ to $600{ }^{\circ} \mathrm{C}$ (heating rate of $10{ }^{\circ} \mathrm{C} \mathrm{min}-1$ ) under an inert nitrogen atmosphere (flow rate of $\left.50 \mathrm{~mL} \min ^{-1}\right)$.

\section{Differential Scanning Calorimetry (DSC)}

The glass transition temperature for uncross-linked and crosslinked GG films were determined by DSC (Shimadzu model DSC-50). Firstly, samples with ca. $10 \mathrm{mg}$ were heated $\left(20^{\circ} \mathrm{C} / \mathrm{min}\right)$ from room temperature to $200{ }^{\circ} \mathrm{C}$. The samples were then cooled with liquid nitrogen to $-50{ }^{\circ} \mathrm{C}$ and re-heated to $130{ }^{\circ} \mathrm{C}$ at $10^{\circ} \mathrm{C} / \mathrm{min}$. Both, scans were carried out under nitrogen flow $(50 \mathrm{~mL} / \mathrm{min})$ and the $\mathrm{Tg}$ values were obtain from the second run.

\section{Mechanical analysis}

The mechanical properties were analyzed on a Universal Testing Machine (EMIC-DL-2000). The samples of each film composition were tested according to the ASTM D882-95a method. Before the tests, the samples were maintained for 15 days at $20 \pm 5{ }^{\circ} \mathrm{C}$ and at $47 \pm 5 \%$ of relative humidity, and a set of twelve specimens from each sample was tested.

\section{Results and Discussion}

\section{Cross-linking of guar gum films}

The efficiency of the cross-linking process is, in general, evaluated through the decrease in the polysaccharide and protein solubility. In our case, the uncross-linked films of GG were totally soluble in water, while after the cross-linking process the films were almost insoluble and maintained their integrity after immersion in water. The solubility values, evaluated through the mass loss of the GG films with $10 \%, 20 \%$ and $30 \%$ (w/w) of EDC, were $27.7 \%$, $25.0 \%$ and $24.3 \%$, respectively. The average solubility of the crosslinked films was thus $c a .26 \%$, indicating that the cross-linking process was efficient, which is in agreement with the results for the water vapor absorption and swelling behavior discussed below. Similar results were obtained by Marquié et al. ${ }^{[28]}$ for films formed from cotton proteins, in which the solubility decreased to $30 \%$ after cross-linking with formaldehyde. Galietta et al. ${ }^{[29]}$ observed a decrease in solubility from 43 to $30 \%$ in milk whey protein-based films treated with formaldehyde as compared to the unmodified film. In another study, unmodified fish-skin gelatin films, which are totally soluble in water at $25{ }^{\circ} \mathrm{C}$, showed $27 \%$ of solubility after cross-linking with transglutaminase (TGase). Similarly, the solubility of fish-skin gelatin/chitosan films at $25{ }^{\circ} \mathrm{C}$ and $\mathrm{pH} 6$ decreased from $65 \%$ to $26 \%$ and $21 \%$ after cross-linking with TGase and EDC, respectively ${ }^{[25]}$.

The proposed mechanism for the cross-linking of GG films (A) is depicted in Figure 1. The carbodiimide (B) is electrophilic and 

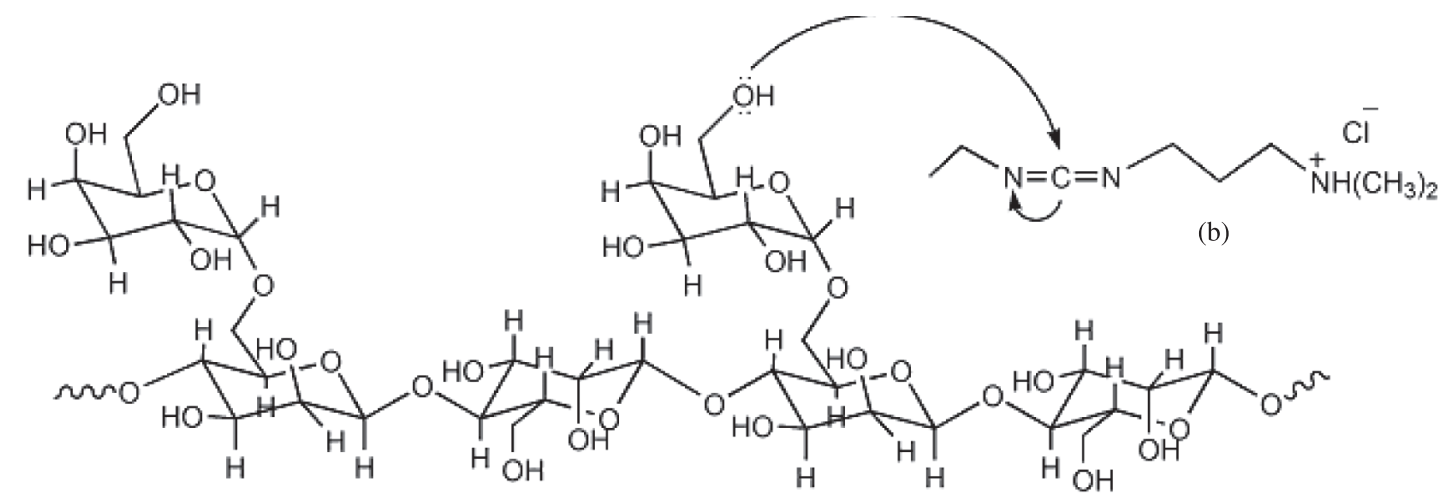

(a)

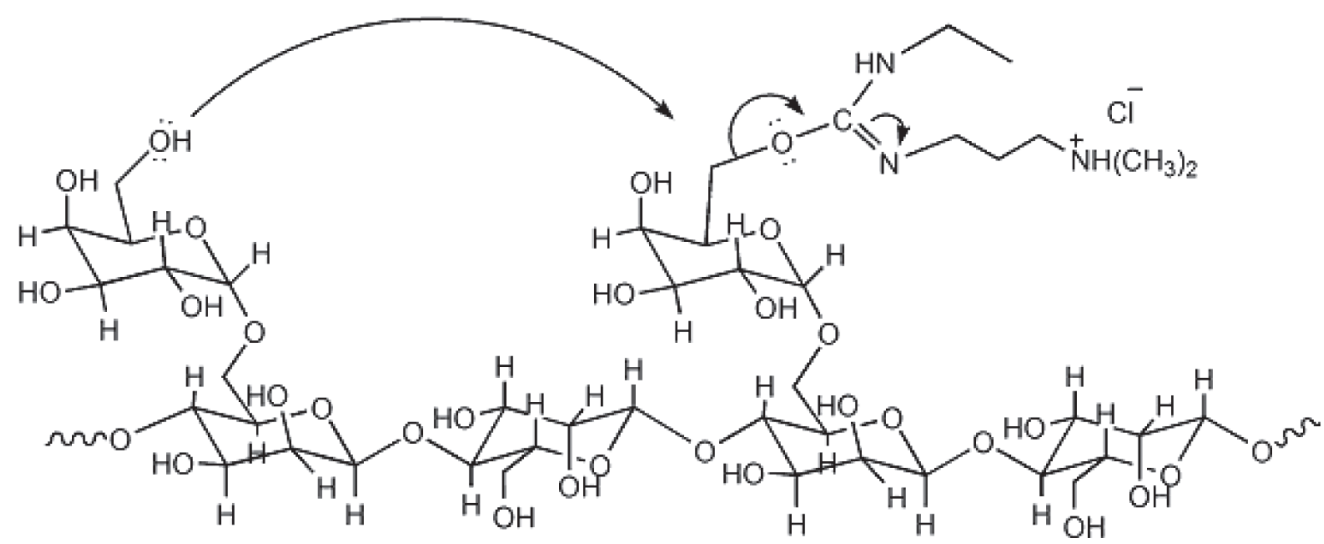

(c)

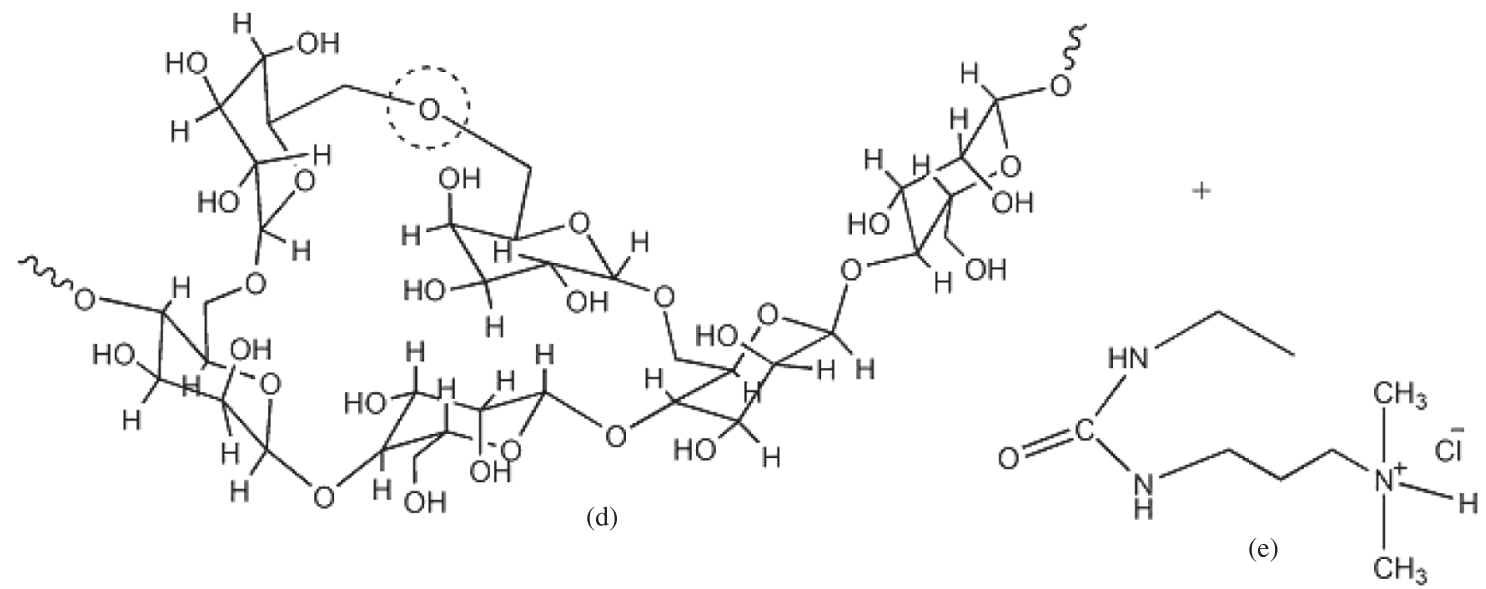

Figure 1. Schematic representation of the proposed mechanism for the reaction between guar gum and EDC. 
firstly undergoes a nucleophilic attack by the hydroxyl groups of the GG, with the formation of a pre-derived urea compound as an intermediate (C). A second nucleophilic attack by $\mathrm{OH}$ groups on the electrophilic carbon of the intermediate then occurs, releasing the urea as an output group. In the cross-linking reaction new ether linkages are formed in the GG structure (D), with a urea derivative as a by-product $(\mathrm{E})^{[21,30,31]}$. The cross-linking mechanism is associated with a reduction in the number of hydroxyl groups in GG. This process is responsible for the decrease in the affinity of GG toward water, decreasing, as a consequence, its solubility. On the other hand, the by-product formed is an ionic compound, easily removed by washing with water.

The formation of a urea derivative and, thus, the success of the cross-linking process, were confirmed by UV spectroscopy (data not shown). The EDC aqueous solution showed an absorption band at $213 \mathrm{~nm}$ which was not observed in the solution of the washed cross-linked films. The washed film solutions were also analyzed to confirm the presence of the urea derivative. The solution showed absorption bands at between $260-280 \mathrm{~nm}$, which corresponds to the UV absorption of urea ${ }^{[32]}$.

The cross-linking of GG was also confirmed by FTIR spectroscopy. In Figure 2 the spectra of pure GG, GG/EDC 20\% (w/w) and washed GG/EDC 20\% (w/w) films are shown. The spectrum of the pure GG (spectrum A) showed absorption bands associated with the stretching vibration of $-\mathrm{OH}$ in the $3600-3200 \mathrm{~cm}^{-1}$ region, $-\mathrm{CH}$ in the $3000-2800 \mathrm{~cm}^{-1}$ region and at $1419 \mathrm{~cm}^{-1}$ (bending vibration), bending vibration of $-\mathrm{OH}$ at $1640 \mathrm{~cm}^{-1}$ and stretching vibration of $\mathrm{C}-\mathrm{OH}$ at 1020,1070 and $1155 \mathrm{~cm}^{-1[33-35]}$. After cross-linking with EDC (spectrum B) new bands at $2125 \mathrm{~cm}^{-1}(-\mathrm{N}=\mathrm{C}=\mathrm{N}-$ ), $1700 \mathrm{~cm}^{-1}$ (carbonyl group) and $1565 \mathrm{~cm}^{-1}(\mathrm{~N}-\mathrm{H})$ associated with a stable amide such as $\mathrm{N}$-acylurea, were observed. According to the mechanism shown in Figure 1, N-acylurea is expected to be formed as a result of the reaction of carboxyl groups of GG with an excess of carbodiimide ${ }^{[36-38]}$. In this study, the molar concentration of EDC used in the cross-linking reaction was around 20 times higher than that of the carboxyl groups of GG.

As previously mentioned, EDC is not incorporated into the lattice structure of the polysaccharide and the excess along with the $\mathrm{N}$-acylurea can be removed by washing the films with water. Indeed, after the washing process, the bands related to the water-soluble $\mathrm{N}$-acylurea were not observed (as expected, spectrum $\mathrm{C}$ is similar to spectrum A), confirming the proposed cross-linking mechanism (Figure 1).

The cross-linking process was also evaluated considering the glass transition temperature ( $\mathrm{Tg}$ ) of the uncross-linked film and those cross-linked with 30\% EDC. The DSC curves (Figure 3) show that the $\mathrm{Tg}$ increased from $12.5^{\circ} \mathrm{C}$ to $38{ }^{\circ} \mathrm{C}$ after the cross-linking process. In fact, several authors have reported similar results, suggesting that the increase in the $\mathrm{Tg}$ is associated with the crosslinking process ${ }^{[29,39]}$. For example, an increase in the $\mathrm{Tg}$ has been previously observed for polyurethane-carboxymethylated guar gum films after cross-linking with calcium chloride ${ }^{[40]}$.

In general, it is accepted that the Tg increases when cross-links are formed in a system, due to the restriction of the polymer chain mobility and the consequent increase in the rigidity of the system ${ }^{[41]}$. The above results are consistent with the results obtained for the FTIR analysis and solubility behavior, confirming that the process used for the cross-linking of GG by EDC was efficient.

\section{Water absorption}

The water absorption of cross-linked GG films was analyzed considering the swelling (SW) behavior and the water vapor absorption (WVA). As previously described, the uncross-linked films were fully soluble in water and for this reason the water absorption was analyzed only in the case of the cross-linked films.

The results for the SW of GG films with different amounts of EDC are shown in Figure 4. The SW decreased by a factor of approximately 1.6 when the amount of EDC used to cross-link the films increased

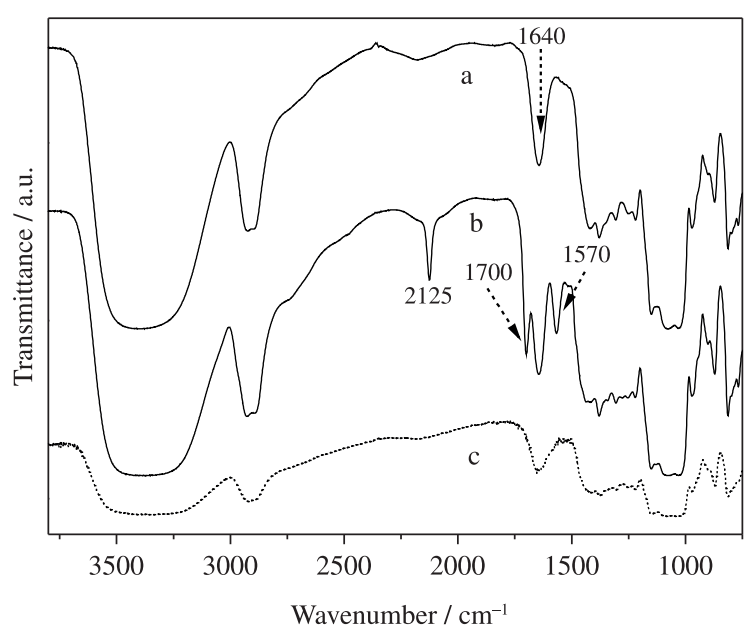

Figure 2. FTIR spectra of: (a) pure GG; (b) GG film cross-linked with $20 \%$ EDC, and (c) same as sample B after washing with water.

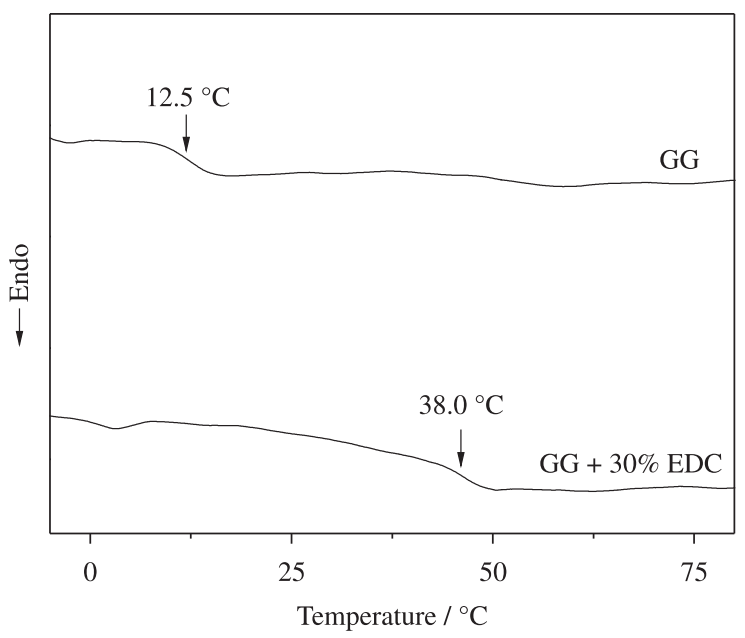

Figure 3. DSC curves of uncross-linked GG film and GG film cross-linked with $30 \%$ EDC.

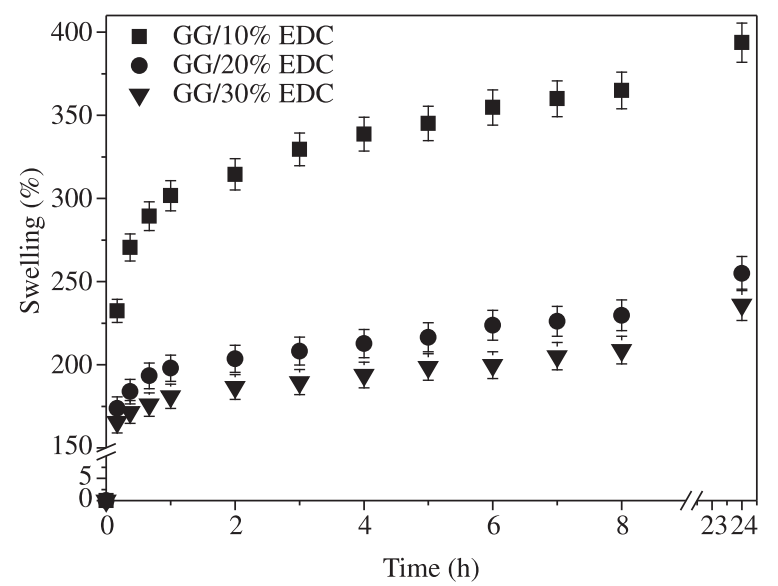

Figure 4. Swelling behavior of GG films with 10, 20 and 30\% (w/w) of EDC. 
from 10 to $30 \%$ (absorptions of $395 \%$ to $235 \%$ after 24 hours, respectively). This behavior is associated with the hydrophilic character of the films, which changed according to the percentage of EDC added to the system. Although the solubility of the crosslinked films (range of 10-30\% EDC) is almost the same (ca. 26\%), the degree of cross-linking seems to differ, i.e., more hydroxyl groups are available in the GG/EDC $10 \%$ system when compared with GG/EDC $30 \%$. The presence of a higher number of free hydroxyl groups favors the interaction with water molecules, which probably occurs through hydrogen bonding, increasing the SW.

In Figure 5 the WVA curves for the GG systems with 10\%, 20\% and $30 \%$ of EDC are shown. A similar trend in the SW behavior was observed, i.e., the guar gum films with $30 \%$ of EDC showed a lower WVA when compared to the system with $10 \%$ EDC. However, the effect on the WVA was less significant than that on the SW. For example, for the GG/EDC $10 \%$ film the SW and WVA were $c a$. $380 \%$ and $115 \%$, respectively. On increasing the amount of crosslinker to 20 and $30 \%$, the percentage of WVA decreased to 90 and $75 \%$, respectively, after 144 hours.

On analyzing Figures 4 and 5 it can be observed that the absorption equilibrium was not totally reached after 24 hours and 144 hours for the SW and WVA, respectively. However, the SW of guar gum cross-linked with $10 \%$ EDC reached equilibrium in two hours $(315 \%)$, which corresponds to approximately $80 \%$ of the total water absorbed in 24 hours $(395 \%)$. For the same system, the WVA reached approximately $80 \%$ of the total absorbed $(115 \%$ in 144 hours) in 24 hours, suggesting that the absorption rates are totally different in terms of the two properties studies (SW and WVA).

The above results demonstrate that the guar gum is able to absorb large amounts of water, which is an important characteristic for applications such as drug delivery systems. At the same time, it was demonstrated that the absorption is dependent on the guar gum cross-linking process.

\section{Thermal stability}

The thermal stability of uncross-linked and cross-linked GG films was analyzed and the thermogravimetric parameters are summarized in Table 1. The films of pure GG showed two stages of mass loss within the ranges of $63-98{ }^{\circ} \mathrm{C}$ and $288-327{ }^{\circ} \mathrm{C}$, corresponding to mass loss percentages of $9.5 \%$ and $71.3 \%$, respectively. In the first stage, the percentage of mass loss was assigned to the release of moisture from the films. According to Soppirnath and Aminabhavi ${ }^{[42]}$ the second stage corresponds to the loss of hydroxyl groups as water molecules and scission of the main chain of GG. Gliko-Kabir et al. ${ }^{[15]}$ reported that the thermal degradation of polysaccharides occurs through random scission of the glycosidic bonds, followed by a further decomposition, and the degradation of GG is caused by a sequence of cleavages of galactose and mannose from the GG backbone.

The relative thermal stability of the samples (pure GG and GG cross-linked with different amounts of EDC) was analyzed considering the degradation temperature and residual mass at $600{ }^{\circ} \mathrm{C}$. In comparison with the pure $\mathrm{GG}\left(\mathrm{T}_{2}=330.9{ }^{\circ} \mathrm{C}\right)$, the degradation temperature of the cross-linked samples decreased to values within $280-300{ }^{\circ} \mathrm{C}$, suggesting that the addition of EDC affected the thermal stability of the GG. This effect was observed to be stronger in the cross-linked natural polymers due to changes in the polymer structures. For example, the thermal stability of GG was improved by cross-linking with low amounts of glutaraldehyde, but decreased when high amounts of the same cross-linker were used $^{[15]}$. In agreement with this scenario, in the GG films crosslinked with $10 \%, 20 \%$ and $30 \%$ of EDC, the temperature of the maximum degradation rate for stage 2 decreased to values lower than $300{ }^{\circ} \mathrm{C}$, suggesting a loss of thermal stability. One explanation for this behavior is that with the cross-linking process and, as a consequence, the formation of intra-cross-linking reactions within the GG chain, the hydrogen bonds, and in turn the polymer structure, was affected reducing the thermal stability ${ }^{[15]}$.

\section{Mechanical properties}

In general, the mechanical properties of films obtained from proteins and polysaccharides have been associated with their chemical structure and film stiffness ${ }^{[43,44]}$. The mechanical characteristics are also dependent on additives, such as, plasticizers and cross-linking agents.

Table 2 shows the mechanical parameters obtained for the GG/ EDC films with different amounts of cross-linker. On increasing the percentage of EDC from $10 \%$ to $30 \%$ the TS decreased by $c a$. $64 \%$, while the elongation increased by $c a .45 \%$. The cross-linking process in films generally increases the TS and decreases the percentage of elongation. However, the opposite behavior observed in our case for the GG/EDC system is in agreement with results reported for other polysaccharide and protein systems ${ }^{[23,45]}$. The EDC interacts with hydroxyl groups from the backbone or from the galactose side group, blocking the hydrogen bonding sites on the guar gum and consequently reducing the intermolecular interactions between the polymer molecules. According to the proposed mechanism detailed

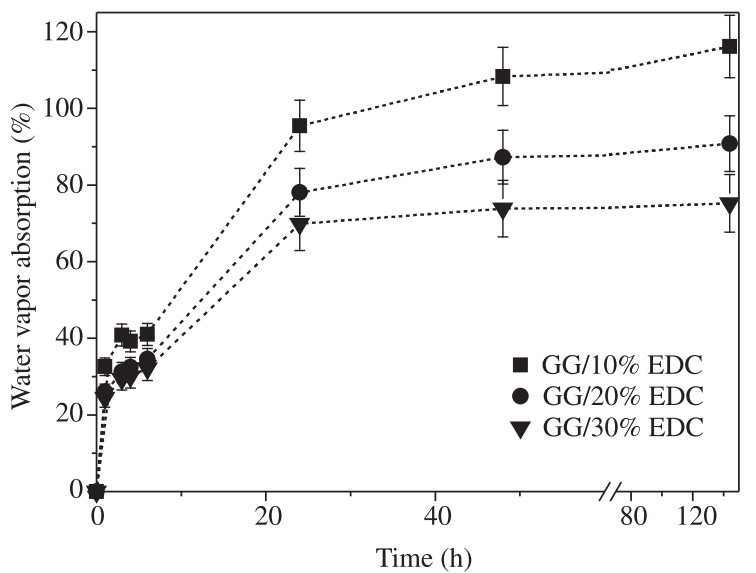

Figure 5. Water vapor absorption of GG films with 10,20 and 30\% (w/w) of EDC.

Table 1. Thermogravimetric parameters of guar gum films.

\begin{tabular}{ccccccc}
\hline \multirow{2}{*}{ Guar gum } & \multicolumn{2}{c}{ Stage $\mathbf{c}$} & \multicolumn{2}{c}{ Stage 2} & Residue $^{(\mathbf{c})}$ \\
\cline { 2 - 5 } & & $\mathbf{T}_{\mathbf{1}}{ }^{(\mathbf{a})}$ & $\mathbf{P}_{\mathbf{1}}{ }^{(\mathbf{b})}$ & $\mathbf{T}_{\mathbf{2}}{ }^{(\mathbf{a})}$ & $\mathbf{P}_{\mathbf{2}}{ }^{(\mathbf{b})}$ & $(\boldsymbol{\%})$ \\
\hline \multirow{4}{*}{ EDC (\%) } & 0 & 71.7 & 9.5 & 330.9 & 71.3 & 19.2 \\
& 10 & 38.7 & 2.8 & 298.7 & 63.7 & 33.5 \\
& 20 & 56.5 & 3.6 & 294.6 & 62.7 & 33.7 \\
& 30 & 46.1 & 6.1 & 284.0 & 61.5 & 32.4 \\
\hline
\end{tabular}

${ }^{(a)}$ Temperature of maximum degradation rate. (b) Percentage of mass loss in each stage of degradation. ${ }^{\left({ }^{c}\right)}$ Residual mass at $600{ }^{\circ} \mathrm{C}$.

Table 2. Mechanical properties of uncross-linked and cross-linked GG/EDC films.

\begin{tabular}{ccccc}
\hline \multicolumn{2}{c}{ Guar gum } & $\begin{array}{c}\text { Tensile } \\
\text { strength (MPa) }\end{array}$ & $\begin{array}{c}\text { Elongation at } \\
\text { break (\%) }\end{array}$ & $\begin{array}{c}\text { Young's } \\
\text { modulus (MPa) }\end{array}$ \\
\hline \multirow{4}{*}{ EDC (\%) } & 0 & $33.7 \pm 1.5$ & $1.7 \pm 0.2$ & $3232.3 \pm 588.0$ \\
& 10 & $43.8 \pm 6.2$ & $2.0 \pm 0.6$ & $2968.7 \pm 652.5$ \\
& 20 & $36.5 \pm 3.6$ & $2.7 \pm 1.4$ & $2135.4 \pm 196.7$ \\
& 30 & $16.0 \pm 1.2$ & $2.9 \pm 1.2$ & $1062.3 \pm 238.5$ \\
\hline
\end{tabular}


above, the EDC interacts with the hydroxyl groups of GG forming ether groups and increasing the chain volume. A similar effect was observed for acetylated GG by Shenoy et al. ${ }^{[46]}$ where simultaneously to the decrease in TS an increase in E occurred. These effects were attributed by the authors to a decrease in free hydroxyl groups due to the ether bonding caused by the acetylation process.

\section{Conclusions}

In this study the effect of the cross-linker EDC on the properties of guar gum films was investigated. EDC appears to be a good cross-linking agent with the advantage of being non-toxic. In terms of the cross-linking mechanism, the incorporation of EDC led to the formation of ether linkages in the guar gum structure, reducing the number of hydroxyl groups available to interact with water, making the structure less polar and consequently reducing its water solubility. The results obtained indicate that the use of guar gum cross-linked with EDC promotes the formation of films with adequate thermal and mechanical properties and appropriate levels of hydration for their application in cell adhesion and drug delivery systems, and these applications will be the subject of further investigation.

\section{Acknowledgements}

The authors gratefully acknowledge the Conselho Nacional de Desenvolvimento Científico e Tecnológico (CNPq) and the Federal University of Santa Catarina (UFSC).

\section{References}

1. Arltoft, D.; Madsen, F. \& Ipsen. R. - Food Hydrocolloid., 21, p.1062 (2007). http://dx.doi.org/10.1016/j.foodhyd.2006.07.020

2. Akhtar, M. \& Dickinson, E. - Food Hydrocolloid., 21, p.607 (2007). http://dx.doi.org/10.1016/j.foodhyd.2005.07.014

3. Nishinari, K. \& Takahashi, R. - Curr. Opin.Colloid In., 8, p.396 (2003). http://dx.doi.org/10.1016/S1359-0294(03)00099-2

4. Barbosa, M. A.; Granja, P. L.; Barrias, C. C. \& Amaral, I. F. - ITBMRBM, 26, p.212 (2005). http://dx.doi.org/10.1016/j.rbmret.2005.04.006

5. Nishikawa, T.; Nishida, J.; Ookura, R.; Nishimura, S-I.; Wada, S.; Karino, T. \& Shimomura, M. - Mater. Sci. Eng. C, 8-9, p.495 (1999). http://dx.doi.org/10.1016/S0928-4931(99)00075-2

6. Dawson, E.; Mapili, G.; Erickson, K.; Taqvi, S. \& Roy, K. - Adv. Drug Deliver. Rev., 60, p.215 (2008). PMid:17997187. http://dx.doi. org/10.1016/j.addr.2007.08.037

7. Peppas, N. A.; Bures, P.; Leobandung, W. \& Ichikawa, H. - Eur. J. Pharm. Biopharm., 50, p.27 (2000). http://dx.doi.org/10.1016/S09396411(00)00090-4

8. Brinker, A. - Aquaculture, 267, p.315 (2007). http://dx.doi. org/10.1016/j.aquaculture.2007.02.037

9. Cunha, P. L. R.; Castro, R. R.; Rocha, F. A. C.; De Paula, R. C. M. \& Feitosa, J. P. A. - Int. J. Biol. Macromol., 37, p.99 (2005). PMid:16221491. http://dx.doi.org/10.1016/j.ijbiomac.2005.09.001

10. McCleary, B. V.; Clark, A. H.; Dea, I. C. M. \& Rees, D. A. - Carbohyd. Res., 139, p.237 (1985). http://dx.doi.org/10.1016/0008-6215(85)90024-2

11. Sandolo, C.; Matricardi, P.; Alhaique, F. \& Coviello T. - Food Hydrocolloid., 23, p.210 (2009). http://dx.doi.org/10.1016/j. foodhyd.2008.01.001

12. Johnson, F. M. - Environ. Mol. Mutagen., 39, p.69 (2002). PMid:11813298. http://dx.doi.org/10.1002/em.10037

13. Coviello, T.; Alhaique, F.; Dorigo, A.; Matricardi, P. \& Grassi, M. - Eur. J. Pharm. Biopharm., 66, p.200 (2007). PMid:17156985. http://dx.doi. org/10.1016/j.ejpb.2006.10.024
14. Young, S.; Wong, M.; Tabata, Y. \& Mikos, A. G. - J. Control. Release, 109, p.256. (2005). PMid:16266768. http://dx.doi.org/10.1016/j. jconrel.2005.09.023

15. Gliko-Kabir, I.; Penhasi, A. \& Rubinstein, A. - Carbohyd. Res., 316, p.6. (1999). http://dx.doi.org/10.1016/S0008-6215(99)00025-7

16. Gliko-Kabir, I.; Yagen, B.; Penhasi, A. \& Rubinstein, A. J. - Control. Release, 63, p.121 (2000). http://dx.doi.org/10.1016/S01683659(99)00179-0

17. Gliko-Kabir, I; Yagen, B.; Penasi, A.; Rubinstein, A. - Pharmaceut. Res., 15, p.1019 (1998). PMid:9688054. http://dx.doi. org/10.1023/A:1011921925745

18. Burruano, B. T.; Schnaare, R. L. \& Malamud, D. - Contraception, 66, p.137 (2002). http://dx.doi.org/10.1016/S0010-7824(02)00336-0

19. Chaurasia, M.; Chourasia, M. K; Jain, N. K.; Jain, A.; Soni, V.; Gupta, Y. \& Jain, S. K. - AAPS PharmSciTech. , 7, p.74 (2006). PMid:17025254.

20. Lee, J. M.; Edwards, H. H. L.; Pereira, C. \& Samii, S. I. - J. Mater. SciMater. M., 7, p.531 (1996).

21. Choi, Y. S.; Hong, S. R.; Lee, Y. M.; Song, K. W.; Park, M. H. \& Nam, Y. S. - J. Biomed. Mater. Res., 48, p.631 (1999). http://dx.doi.org/10.1002/ (SICI)1097-4636(1999)48:5<631::AID-JBM6>3.0.CO;2-Y

22. Cascone, M. G.; Sim, B. \& Sandra, D. - Biomaterials, 16, p.569 (1995). http://dx.doi.org/10.1016/0142-9612(95)91131-H

23. Liang, H. C.; Chang, W. H.; Liang, H. F.; Lee, M. H. \& Sung. H. W. - J. Appl. Polym. Sci., 91, p.4017 (2004). http://dx.doi.org/10.1002/ app. 13563

24. Liu, X.; Smith, L. A.; Hu, J. \& Ma, P. X. - Biomaterials, 30, p.2252 (2009). PMid:19152974 PMCid:2679864. http://dx.doi.org/10.1016/j. biomaterials.2008.12.068

25. Kolodziejska, I. \& Piotrowska, B. - Food Chem., 103, p.295 (2007).

26. Cunha, P. L. R.; Paula, R. C. M. \& Feitosa, J. P. A. - Int. J.Biol. Macromol., 41, p.324 (2007). PMid:17531313. http://dx.doi. org/10.1016/j.ijbiomac.2007.04.003

27. Angles, M. N. \& Dufresne, A. - Macromolecules, 33, p.8344 (2000). http://dx.doi.org/10.1021/ma0008701

28. Marquie, C.; Ayrmard, C.; Cuq, J. L. \& Guilbert, S. - J. Agr. Food Chem., 43, p.2762 (1995). http://dx.doi.org/10.1021/jf00058a040

29. Galietta, G.; Di-Gioia, L.; Guilbert, S. \& Cuq, B. - J. Dairy Sci., 81, p.3123 (1998). http://dx.doi.org/10.3168/jds.S0022-0302(98)75877-1

30. Sannino, A.; Pappadà, S.; Madaghiele, M.; Maffezzoli, A.; Ambrosio, L. \& Nicolais, L. - Polymer, 46, p.11206 (2005). http://dx.doi. org/10.1016/j.polymer.2005.10.048

31. Tejado, A.; Antal, M.; Liu, X. \& Van de Ven, T. G. M. - Ind. Eng. Chem. Res., 50, p.5907 (2011). http://dx.doi.org/10.1021/ie1023589

32. Uhlin, F.; Fridolin, I.; Lindberg, L. G. \& Magnusson, M. - Nephrol. Dial. Transpl., 20, p.2458 (2005). PMid:16077147. http://dx.doi. org/10.1093/ndt/gfi026

33. Mundargi, R. C.; Agnihotri, S. A.; Patil, S. A. \& Aminabhavi, T. M. - J. Appl. Polym. Sci., 101, p.618 (2006). http://dx.doi.org/10.1002/ app. 23325

34. Wang, W.; Zhang, J. \& Wang, A. - Appl. Clay Sci., 46, p.21 (2009). http://dx.doi.org/10.1016/j.clay.2009.07.001

35. Copikova, J.; Synytsya, A.; Cerna, M.; Kaasova, J. \& Novotna, M. - Czech J. Food Sci., 19, p.51 (2001).

36. Li, Z-F.; Li, J-Y.; Sun, J.; Sun, B-Q.; Wang, J-J. \& Shen, Q. - Front. Mater. Sci. China, 2, p.200 (2008). http://dx.doi.org/10.1007/s11706008-0033-5

37. Jena, K. K.; Chattopadhyay, D. K. \& Raju, K. V. S. N. - Eur. Polim. J., 43, p.1825 (2007). http://dx.doi.org/10.1016/j.eurpolymj.2007.02.042

38. Zhang, R. - Polymer, 46, 2443 (2005). http://dx.doi.org/10.1016/j. polymer.2005.02.006 
39. Martucci, J. F.; Ruseckaite, R. A. \& Vazquez, A. - Mater. Sci. Eng. A, 435-436, p.681 (2006). http://dx.doi.org/10.1016/j.msea.2006.07.097

40. Huang, Y.; Yu, H. \& Xiao, C. - Carbohyd. Polym., 66, p.500 (2006). http://dx.doi.org/10.1016/j.carbpol.2006.04.001

41. Akcelrud, L. - "Fundamentos da ciência dos polímeros", 1st ed., Manole, Barueri, p.288 (2007).

42. Soppirnath, K. S. \& Aminabhavi, T. M. - Eur. J. Pharm. Biopharm., 53, p.87 (2002). http://dx.doi.org/10.1016/S0939-6411(01)00205-3

43. Debeaufort, F. \& Voilley, A. - J. Agric. Food Chem., 45, p.685 (1997) http://dx.doi.org/10.1021/jf9606621
44. Sothornvit, R. \& Krochta, J.M. - J. Food Eng., 50, p.149 (2001). http:// dx.doi.org/10.1016/S0260-8774(00)00237-5

45. Cristiano, C. M. Z.; Fayad, S. J.; Porto, L. C. \& Soldi, V. - J. Bras. Chem. Soc., 21, p.340 (2010). http://dx.doi.org/10.1590/S010350532010000200021

46. Shenoy, M. \& D’Melo, D. J. - E-polymers, 1, p.111 (2007).

Received: $16 / 05 / 12$

Revised: 03/10/12

Accepted: 10/10/12 